\title{
Assessment of Perinatal Mortality in a Tertiary Care Hospital by Using Wigglesworth Classification
}

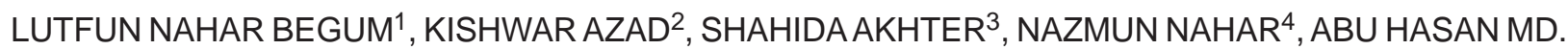 \\ ABDULLAH ${ }^{5}$
}

\begin{abstract}
Objective: To determine the causes of perinatal death using Wigglesworth classification and to assess the feasibility of using Wigglesworth classification in a tertiary care hospital setting.

Methods: All live and stillborn babies delivered at BIRDEM over a 5 yr period(from January 2000 to December 2004) were recorded. Perinatal deaths of that period were analysed according to Wigglesworth classification

Results: According to Wigglesworth classification, majority of deaths were in the group "macerated stillbirths"(63.5\%). Perinatal asphyxia was responsible for 13.6\% of deaths, lethal congenital malformation was found in $11.2 \%$ and immaturity and "others" each accounted for $6.1 \%$.

Conclusion: Macerated stillbirth and asphyxia were the two leading causes of death at BIRDEM and Wigglesworth classification has been found to be feasible in BIRDEM for categorising perinatal deaths retrospectively.
\end{abstract}

Key words: Perinatal death, Wigglesworth classification

\section{Introduction}

Bangladesh has one of the highest infant mortality rates in the world. Between 2002-2006, the infant mortality rate was 52 per 1000 live births and neonatal mortality rate was 37 per 1000 live births ${ }^{1}$. Perinatal mortality is also particularly high in Bangladesh. As infant mortality has declined, deaths during the perinatal period have become a more important public health problem. No national statistics are available for perinatal mortality rate (PMR). Demographic surveillance data from the Center for Population and Health Research of ICDDR,B reflects the situation prevailing in the community. Fauveau et $\mathrm{al}^{2,3}$ carried out one of the the first studies of perinatal mortality in Matlab, from 1979 to 1986 . They reported an overall PMR of 75 per 1000 total births (live births and stillbirths), with stillbirths and early neonatal mortality rates each comprising $50 \%$. There have been a number of hospital studies, which give varying figures. The PMR from a 1993 paper ${ }^{4}$ reviewing 20119 deliveries at Dhaka Medical College Hospital was 143 per 1000 total births. Very high PMR was also reported from Rajshahi Medical College Hospital ${ }^{5}$ with 151 per 1000 live births.

The PMR is a reflection of a country's obstetric and neonatal services and is determined by many factors ${ }^{6-}$
8. These include genetic, social and environmental factors which determine adequacy of fetal growth and nutrition, risk of malformation, infection and preterm birth and quality or level of utilization of obstetric and neonatal care services ${ }^{6}$. It is however increasing recognized that many factors determine perinatal outcome. This has made analysis of perinatal data difficult and limited the evaluation of any intervention ${ }^{9}$. In addition, the overall reliability of perinatal mortality data may be low. There is widespread under-reporting of stillbirths and early neonatal deaths which fail to appraise planners of the dimension of the problem.

Many classification systems have been developed in order to analyze perinatal mortality data. Wigglesworth in $1980^{9}$ devised a simple, reproducible method of classifying perinatal deaths (shown below).

Wigglesworth classification of Perinatal deaths ${ }^{9}$ :

1. Normally formed macerated (SB)

2. Congenital malformation (SB or NND)

3. Conditions associated with immaturity (NND)

4. Asphyxial conditions developing in labour (fresh SB/NND)

5. Specific conditions other than above.

( $\mathrm{SB}=$ stillbirth, NND = neonatal deaths $)$.

1. S. Registrar, Paediatrics \& Neonatology. Apollo Hospitals, Dhaka.

2. Director of Perinatal Care Project, Senior Honorary Consultant, Department of Pediatrics, BIRDEM, Dhaka

3. Associate Professor, Department of Paediatrics, BIRDEM, Dhaka

4. Professor, Department of Paediatrics, BIRDEM, Dhaka

5. Ex. Assistant Professor, Department of Paediatrics, BIRDEM, Dhaka 


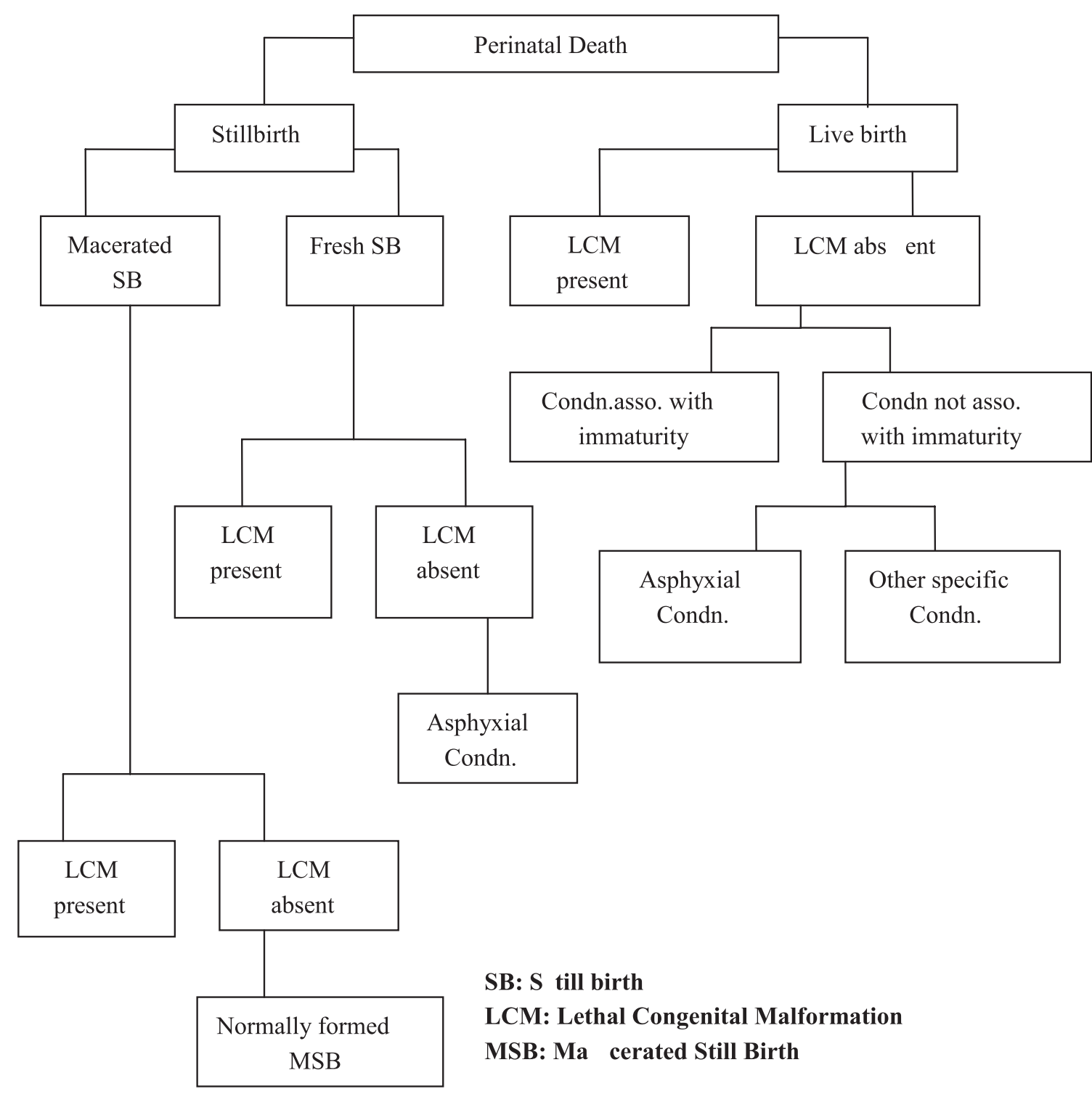

Flow Chart to classify perinatal death by using Wigglesworth Classification

Although Wigglesworth admitted that necropsy would permit the most accurate categorization, his classification was devised such that the need for necropsy was obviated. Necropsies are extremely difficult to obtain in Bangladesh because of cultural and religious belief. Therefore, this study was conducted to determine.

The causes of perinatal death by using Wigglesworth classification and assess the feasibility of using this classification in a tertiary care hospital setting.

Materials and Methods:

This retrospective study was carried out 5 yrs over a period from January 2000 to December 2004 at Special
Care Baby Unit (SCABU) and Obstetric \& Gynaecological Department of Bangladesh Institute of Research and Rehabilitation in Diabetes, Endocrine and Metabolic disorders (BIRDEM). All live and stillborn babies delivered at BIRDEM were included in this study. Babies delivered outside BIRDEM were excluded.

All babies delivered at BIRDEM and their mode of delivery over a 5 year period from January 2000 to December 2004 were recorded from register book at obstetric department. Among them all stillbirth cases were identified and their weight, sex, gestational age (from last menstrual period), mode of delivery, presence of any lethal congenital anomalies, type of stillbirth (macerated or fresh) were recorded from the 
register book. In case of early neonatal death, who died within 7 days of delivery were identified from record books kept in SCABU. Their sex, weight, gestational age (as determined by modified ballard score), congenital anomalies were recorded and cause of deaths were noted as recorded in the death note. In BIRDEM, all caesarian deliveries and some high risk vaginal deliveries were attended by a resident pediatrician and management of ill babies started from birth. Everyday one doctor from SCABU used to visit the postnatal ward. If any baby developed any illness during hospital stay, he/she was admitted in SCABU for further management. In each case of death and discharge, a details history, clinical observation and investigations were noted in the record book. A structured questionnaire was filled for each death case from this record book.

The perinatal deaths were analysed according to Wigglesworth classification into five catagories, viz macerated stillbirth (normally formed), lethal congenital malformation, asphyxial conditions, prematurity and other causes. Since, the influence of birthweight on mortality is particularly marked in very low birthweight babies, data were collected as far as possible. Babies were grouped on the basis of birth weight, e.g, <1000g, 1000-1500g, 1501-2000g, 2001-2500g, >2500g. They were also grouped on the basis of gestational age, e.g. <30wks, 31-34wks, 35-37wks and >37wks.

The babies who were discharged before 7 days of postnatal period were considered live as the hospital used to discharge newborn only when they were screened healthy and normal.

The stillbirth rate, early neonatal mortality rate, perinatal mortality rate were calculated in different years, where denominator included all births, including those who were discharged before 7th postnatal day.

Data entry and consistency check were done manually.

\section{Operational definitions:}

Perinatal death: WHO recommends that national perinatal statistics should include all fetuses and infants delivered weighing at least $500 \mathrm{~g}$ or when birthweight is unavailable the corresponding gestational age (22 weeks) or body length $(25 \mathrm{~cm}$ crown-heel), whether alive or dead ${ }^{10}$. Thus, Perinatal Mortality Rate (PMR) has been defined as fetal deaths weighing $500 \mathrm{~g}$ or more plus deaths occuring less than 7 completed days after birth per 1000 total births. However, there is no universally accepted definition of PMR.
Stillbirth is the death of a fetus weighing at least $500 \mathrm{~g}$ (or when birth weight is unavailable, after 22 completed weeks of gestation or with a crown-heel length of 25 $\mathrm{cm}$ or more).

Macerated stillbirth: Fetal death occur within the uterus before the onset of labour.

Fresh stillbirth: Fetal death occur within the uterus during labour and delivery ${ }^{10}$.

\section{Results}

A total of 5598 deliveries took place at BIRDEM during the study period. A large proportion of babies were delivered by caesarean section (78\%). Among 5598 births ,191cases (3.4\%) were stillbirths and 86 cases (1.5\%) were early neonatal deaths. A decreasing trend of early neonatal death was found in this study. Perinatal deaths were highest in 2002. The predominant sex was male in this group. Male: female ratio with 1.4:1. The sex of 2 babies were ambiguous. Majority of the stillbirths were delivered per vaginally (78\%). In case of early neonatal deaths, male: female ratio was 1.2:1 and majority were delivered by caesarian section (73.3\%).

Perinatal deaths were analysed (Table-II) according to Wigglesworth classification. Majority of deaths were in the group ' normally formed macerated stillbirths' (63.5 \%). Perinatal asphyxia caused for $13.6 \%$ of deaths, lethal congenital malformation $11.2 \%$ and immaturity and 'others' each accounted for $6.1 \%$. In the 'others' category, 7 babies died due to septicemia, 6 babies due to RDS, 3 babies due to aspiration of feeding and one baby due to hydrops fetalis. Lethal congenital malformations were detected in $14(7 \%)$ cases of stillbirths. These cases were included in the lethal congenital malformation group. Early neonatal deaths (within 7 days) were also grouped (Table-III) according to the causes of death. The most common cause of death was asphysia (40\%). Perinatal deaths were also grouped according to birthweight (Table-IV) as proposed by Wigglesworth. Asphyxia and septicemia were the two most common causes in babies weighing 1000-2000g. In addition to weight, perinatal deaths were also classified according to gestational age (Table-V). Maximum deaths occurred in preterm babies ( $<37 \mathrm{wks})$, There was an inverse relation between gestational age and deaths.

The feasibility of use of Wigglesworth classification in this study was analysed(table-VI). In the record book, all parameters were recorded properly, except still births cases. Still birth cases were not recorded as macerated or fresh. Majority were recorded as IUD. 
Table - I

Perinatal death rate from 2000 to 2004

\begin{tabular}{lccccc}
\hline Year & $\begin{array}{c}\text { Total births } \\
\mathrm{n}=5598\end{array}$ & $\begin{array}{c}\text { Still births } \\
\mathrm{n}=191\end{array}$ & $\begin{array}{c}\text { Early neonatal deaths } \\
\mathrm{n}=86\end{array}$ & $\begin{array}{c}\text { Perinatal deaths } \\
\mathrm{n}=277\end{array}$ & $\begin{array}{c}\text { Perinatal death } \\
\text { rate per 1000 births }\end{array}$ \\
\hline 2000 & 1141 & 33 & 22 & 55 & 48.2 \\
2001 & 1174 & 32 & 16 & 48 & 40.9 \\
2002 & 1031 & 49 & 23 & 72 & 69.8 \\
2003 & 1136 & 40 & 13 & 53 & 46.7 \\
2004 & 1116 & 37 & 12 & 49 & 43.9 \\
\hline
\end{tabular}

Table- II

Perinatal deaths according to wigglesworth classification

\begin{tabular}{|c|c|c|c|c|c|c|}
\hline \multicolumn{2}{|c|}{ Causes of deaths $n=277(100 \%)$} & 2000 & 2001 & 2002 & 2003 & 2004 \\
\hline \multicolumn{2}{|c|}{ *Macerated StillbirthsN =177 (63.5\%) } & 29 & 29 & 47 & 37 & 35 \\
\hline \multicolumn{2}{|l|}{ + Asphyxian=35 (13\%) } & 11 & 8 & 7 & 6 & 3 \\
\hline \multicolumn{2}{|l|}{ Immaturity n=17 (6.1\%) } & 3 & 1 & 8 & 3 & 2 \\
\hline \multicolumn{2}{|c|}{ **Congenital anomalyn=31 (11.2\%) } & 10 & 5 & 6 & 5 & 5 \\
\hline \multirow[t]{4}{*}{ Others $(n=17)(6.2 \%)$} & sepsis $n=7(2.5 \%)$ & - & - & 2 & 2 & 3 \\
\hline & $\operatorname{RDS} n=6(2.2 \%)$ & 2 & 2 & 2 & - & - \\
\hline & aspiration of feedingn=3 (1.1\%) & - & 2 & - & - & 1 \\
\hline & hydrops fetalisn=1 $(0.4 \%)$ & - & 1 & - & - & - \\
\hline
\end{tabular}

* All stillbirth cases except lethal congenital anomaly (in record book, still birth cases were not recorded as macerated or fresh)

+ Only asphyxiated live born babies

** 14 cases of still birth, who had congenital anomales included in this group

Table -III

Causes of early neonatal deaths( within 7 days)

\begin{tabular}{llccccc}
\hline Causes of deathn=86 (100\%) & 2000 & 2001 & 2002 & 2003 & 2004 \\
\hline Asphyxian=35 (40\%) & 11 & 8 & 7 & 6 & 3 & \\
Immaturity $\mathrm{n}=17(20 \%)$ & 3 & 1 & 8 & 3 & 2 & \\
Congenital anomalyn=17 (20\%) & 6 & 2 & 4 & 2 & 3 \\
Others $(\mathrm{n}=17)(20 \%)$ & sepsis $\mathrm{n}=7(8.2 \%)$ & - & - & 2 & 2 & 3 \\
& RDS $\mathrm{n}=6(7 \%)$ & 2 & 2 & 2 & - & - \\
& aspiration of feedingn=3 (3.5\%) & - & 2 & - & - & 1 \\
& hydrops fetalisn=1 (1.2\%) & - & 1 & - & - & - \\
\hline
\end{tabular}


Table - IV

Perinatal deaths according to birthweight

\begin{tabular}{|c|c|c|c|c|c|}
\hline $\begin{array}{l}\text { Birth weight } \\
\text { (gms)n=277 }\end{array}$ & $\begin{array}{c}\text { Stillbirths } \\
n=177 \\
(63.9 \%)\end{array}$ & $\begin{array}{c}\text { Lethal congenita } \\
\text { malformation } \\
\mathrm{n}=31 \\
(11.2 \%)\end{array}$ & $\begin{array}{l}\text { Condition associa } \\
\text { with immaturity } \\
n=17(6.1 \%)\end{array}$ & $\begin{array}{c}\text { dAsphyxial } \\
\text { conditions } \\
n=35 \\
(12.6 \%)\end{array}$ & $\begin{array}{c}\text { Other specific } \\
\text { onditions } n=17 \\
(6.1 \%)\end{array}$ \\
\hline $\begin{array}{l}<1000 n=63 \\
(22.7 \%)\end{array}$ & $42(66.7 \%)$ & $4(6.3 \%)$ & $17(27 \%)$ & - & - \\
\hline $\begin{array}{l}1000-1500 n=50 \\
(18.1 \%)\end{array}$ & $30(60 \%)$ & $3(6 \%)$ & - & $12(24 \%)$ & $\begin{array}{l}\text { 3-sepsis } \\
\text { 2-RDS }\end{array}$ \\
\hline $\begin{array}{l}1501-2000 \\
n=42 \\
(15.2 \%)\end{array}$ & $18(42.8 \%)$ & $7(16.7 \%)$ & - & $12(28.6 \%)$ & $\begin{array}{l}\text { 3-sepsis } \\
\text { 1-RDS } \\
\text { 1-hydrops }\end{array}$ \\
\hline $\begin{array}{l}2001-2500 n=62 \\
(22.4 \%)\end{array}$ & $43(69.3 \%)$ & $9(14.5 \%)$ & - & $6(9.7 \%)$ & $\begin{array}{c}\text { 1-sepsis } \\
\text { 3-RDS }\end{array}$ \\
\hline $\begin{array}{l}>2500 \mathrm{n}=60 \\
(21.7 \%)\end{array}$ & $44(73.3 \%)$ & $8(13.3 \%)$ & - & $5(8.3 \%)$ & 3-aspiration \\
\hline
\end{tabular}

Table-V

Perinatal deaths according to gestational age

\begin{tabular}{lccc}
\hline Gestational age (wks) & Still birth $\mathrm{n}=191$ & Early neonatal death $\mathrm{n}=86$ & Perinatal death $\mathrm{n}=277$ \\
\hline$\leq 30$ & $53(63.1 \%)$ & $31(37 \%)$ & $84(30.3 \%)$ \\
$31-34$ & $52(69.3 \%)$ & $23(30.7 \%)$ & $75(27.1 \%)$ \\
$35-37$ & $52(74.3 \%)$ & $18(25.7 \%)$ & $70(25.3 \%)$ \\
$>37$ & $34(70.8 \%)$ & $14(29.2 \%)$ & $48(17.3 \%)$ \\
\hline
\end{tabular}

Table-VI

Feasibility of use of wigglesworth classification in this study

\begin{tabular}{ll}
\hline Parameters & Comments \\
\hline Birth weight andGestational age & Recorded in 100\% cases. \\
Stillbirth & $\begin{array}{l}\text { Should be recorded as macerated or fresh. But in record books, majority of } \\
\text { stillbirths were recorded as IUD. One case recorded as fresh stillbirth. }\end{array}$ \\
Congenital anomalies & $\begin{array}{l}\text { Congenital anomalies in stillbirth cases were recorded in register books as } \\
\text { anencephaly, hydrocephalus, multiple congenital anomalies etc. These } \\
\text { cases were grouped under lethal congenital anomalies group. }\end{array}$ \\
Immaturity & $<1$ kg babies were included in this group irrespective of the causes of death. \\
Asphyxia & All asphyxia cases were included. \\
Other specific conditions & Sepsis, RDS, aspiration of feed, hydrops were included here.
\end{tabular}




\section{Discussion}

This retrospective study estimated perinatal deaths among babies delivered at BIRDEM Hospital, Dhaka over a 5 year period from January 2000 to December 2004 using Wigglesworth classification and by assessed feasibility of the its use in a hospital setting.

The present study has revealed a perinatal mortality rate of 49.9 per 1000 total births over a period of five years (2000-2004), i.e., 277 perinatal deaths for 5598 births. Stillbirths have remained more or less static during this period. The highest (69.8 per 1000) and lowest (40.9 per 1000 total births ) numbers of perinatal deaths occurred in 2002 and 2001 respectively. Early neonatal mortality rate showed a downward trend although it increased in 2002 due to increased mortality in babies weighing less than 1 $\mathrm{kg}$. Reduction in the early neonatal mortality rate has a major contribution in lowering the perinatal mortality rate. But in each of the 5 years, early neonatal death was consistently lower than still birth.

A number of hospital studies have been carried out in Bangladesh, which give varying figures. Astudy carried out in1993 at Dhaka Medical College Hospital, which is the largest referral hospital in Dhaka city, reviewed 20,119 deliveries; PMR was 143 per 1000 total births ${ }^{4}$. A very high PMR of 151 per 1000 births $^{5}$ was also observed in a study in Rajshahi Medical College Hospital; $78 \%$ of the deaths were stillbirths and $22 \%$ occurred in the first week of life.

In 2001, Azad et al ${ }^{11}$ analysed perinatal deaths using Wigglesworth classification in 5 centers, viz. Dhaka Medical College Hospital (DMCH), Bangabandhu Sheikh Mujib Medical University (BSMMU), BIRDEM Hospital, 200 bedded specialised hospital at Narayangonj, and Bhaluka Upazilla Health Complex. A total of 8058 births were recorded at the 5 centers during a period of 11 months, from mid-January to mid- December 2001. This study used the definition of perinatal deaths as stillbirths occurring at 28 weeks of gestational age or more, (instead of 22 weeks as suggested by $\mathrm{WHO}$ ) and early neonatal deaths before 7 days of life. There were 1069 perinatal deaths; stillbirths were more frequent $(53.5 \%)$ than early neonatal deaths (46.5\%). Some problems were encountered by Azad et al in carrying out their study ${ }^{11}$. At DMCH and Narayangonj, a large number of cases (about $20 \%$ and $60 \%$ respectively) were not recorded. At DMCH, a significant number of stillbirths were not classified. So, proper orientation of the staffs are necessary for good record keeping.
In a community study done at Matlab 2,3 in 1979-86, perinatal mortality rate was quoted as 75 per 1000 total births, with stillbirths and early neonatal deaths contributing equally at 37 and 38 per 1000 total births respectively. This finding contrasted with the majority of hospital studies ${ }^{4,5}$ which showed the opposite, i.e., stillbirths were more frequent than early neonatal deaths. Hospitals usually deal with complicated and late cases of labour and delivery; thus, most stillbirths may be a result of obstructed labour leading to perinatal asphyxia.

In this study, PMR was slightly higher in males than females. Fauveau et $\mathrm{al}^{3}$ and Azad et $\mathrm{al}^{11}$ also showed the same result in their study.

The leading causes of death identified as per Wigglesworth's classification in the present study were perinatal asphyxia and macerated stillbirths which together accounted for more than two-thirds of perinatal mortality. Verma et al ${ }^{12}$ and Pradeep et al ${ }^{13}$ have also noted perinatal hypoxia and macerated stillbirths as major contributors to perinatal mortality. Kumar et $\mathrm{al}^{14}$ and Patel et al ${ }^{15}$ recorded birth asphyxia, infections and prematurity as the three leading causes of deaths.

The increased deaths due to asphyxia may be due to inadequate and inappropriate monitoring and late referral of intra-uterine asphyxia cases. These cases probably would have ended up as stillbirths in the peripheral centers if they did not come to the referral hospital. As BIRDEM is a referral hospital, most of the mothers had one or more high risk factors. Moreover a number of unbooked mothers with intrauterine death were referred to BIRDEM for delivery. This also explains the relatively high stillbirth rate and asphyxial cases. The improvement of neonatal care has helped in reducing the deaths among the low birth weight babies of booked mothers while reverse was the case among babies of unbooked mothers. Kumar et $\mathrm{al}^{14}$ study showed that in 1996, the early neonatal mortality rate (ENMR) has decreased from 20 to 16.3 per 1000 total births among booked cases while it nearly tripled in the unbooked cases. The still birth rate (SBR) is 3 to 4 times more in unbooked cases as compared to booked cases. The PMR is 2 to 3 times higher in unbooked cases than among booked cases. The PMR among unbooked cases was 6 times that of booked cases in the study by Verma et $\mathrm{al}^{12}$. Patel et $\mathrm{al}^{15}$ also found PMR to be 3 times more in mothers with irregular antenatal care. 
Conditions associated with immaturity were responsible for $6.1 \%$ of perinatal death. Azad et al ${ }^{11}$ study showed $13.3 \%$ cases of perinatal death due to immaturity. Reduction in deaths due to prematurity can be attributed to the good neonatal care provided in SCABU. Here staff are well trained and nurse:patient ratio is high in comparison to other hospitals.

In this study, $2.5 \%$ of perinatal deaths were due to sepsis. Sepsis was more frequent in babies weighing 1-2 Kg. More vigorous aseptic precautions, like frequent handwashing, use of disposable equipment and availability of more effective antibiotics and adjuvants, as well as better investigative facilities, may reduce deaths from sepsis. In Singh et al ${ }^{16}$ from India study, 5.6\% perinatal deaths were attributed to sepsis.

Singh et al ${ }^{16}$ used the Wigglesworth classification to categorise perinatal deaths in a tertiary centre in India. They showed that $14.6 \%$ perinatal deaths were due to lethal congenital anomalies. In this study, 31(11.2\%) cases of perinatal deaths were due to lethal congenital anomales; 14 (7.3\%) were stillbirths and 17(19.8\%) were early neonatal deaths.

Mortality due to RDS is low probably because of antenatal use of steroids and good management in BIRDEM. Avoidance of preterm deliveries, use of antenatal steroid in all preterm deliveries, administration of surfactant to preterm babies and ventilation can decrease perinatal death due to RDS.

In this study, maximum deaths were in preterm babies $(<37 \mathrm{wks})$. With decreasing gestation, perinatal deaths progressively increased, being highest in $<30 \mathrm{wks}$, followed by in $30-34$ wks. Verma et al ${ }^{12}$ showed that perinatal mortality was high at 28-32 wks gestation.

The objective of this study was to assess the feasibility of the Wigglesworth classification in catagorising perinatal deaths. One of the advantages of the Wigglesworth method was the ability to classify perinatal deaths without necropsies, which are almost impossible to obtain in Bangladesh. Its simplicity allowed nurses, once trained, to use the classification with little difficulty. These advantages may allow its adoption on a national scale to find out the causes of perinatal deaths.

It is evident that asphyxia and macerated stillbirths continue to be responsible for a large amount of perinatal death in our country. Even though the present study has the limitation of being hospital based, it emphasizes that improving the quality of antenatal and natal care can reduce perinatal mortality.

\section{Conclusion}

By using Wigglesworth classification, macerated stillbirth and asphyxia were the two leading causes of perinatal death at BIRDEM. Wigglesworth classification has been found to be feasible in BIRDEM for categorising perinatal deaths retrospectively . Proper orientation of the staff and computerized record keeping of events should be needed.

\section{References}

1. Bangladesh Demographic and Health Survey 2007. National Institute of Population Research and Training (NIPORT). Mitra and Associates and Macro International, Calverton, Maryland USA. May 2007. P. 25.

2. Fauveau V, Wojtyniak B, Chakraborty J, Sarder AM, Briend A, The effect of maternal and child health and family planning on mortality is prevention enough BMJ 1990; 301: 103-07.

3. Fauveau V, Wojtyniak B, Khan SA, Chakraborty J, Sarder AM. Perinatal mortality in Matlab, Bangladesh: a community-based study. International Journal of Epidemiology 1990; 19: 606-12.

4. Begum K. Analysis of 20,119 deliveries in Dhaka Medical College. Asia Oceania J Obstet Gynaecol.1993; 19:1-6.

5. Rasul $\mathrm{CH}$, Hussain MA, Siddiquey AH, Rahman MS. Perinatal mortality in a teaching hospital.Indian Paediatr 1999; 36: 389-91.

6. Perinatal and neonatal mortality. House of Commons second report from the Social Services Committee 1979-80 vol. 1. H.M. Stationery Office, 1980.

7. State of the World's Newborns: Bangladesh; a publication of Save the Children, 2001.

8. Chamberlian G. Background to perinatal health. Lancet 1979; 17: 1062-63.

9. Wigglesworth JS. Monitoring perinatal mortality. A pathophysiological approach Lancet 1980; 27: 684-86.

10. World Health Organization. Mother-baby package: implementing safe motherhood in countries. FHE/MSM/94.11.Geneva: WHO, 1994. 
11. Azad K, Abdullah AH, Nahar N, Shahidullah M, Banu LA, Roy R R et al. Use of Wigglesworth Classification for the assessment of perinatal mortality in Bangladesh a preliminary study. Bangladesh Medical Research Council Bulletin. 2003; 29(2): 3-10.

12. Verma M, Chatwal J, Chacko B. Perinatal mortality at a tertiary care hospital in Punjab. Indian J Pediatr 1999; 66: 493-97.

13. Pradeep M, Rajam L,Sundevan P. Perinatal mortality - a hospital based study. Indian Pediatr1995; 32:1091-94.
14. Kumar MR, Bhat BV, Oumachigui A. Perinatal mortality trends in a Referral hospital. Indian J Paediatr 1996; 63: 357-61.

15. Sachdev HPS, Iyer PU, Bhargava SK. Secular trends in infant and perinatal mortality in India implications for child survival. Indian Pediatr 1991; 28: 1411-18.

16. Singh M, Deorari AK, Khajuria RC, Paul VK. Perinatal and neonatal mortality in a hospital. Indian J Med Res 1991; 94: 1-5. 